\title{
The effect of ex ante and ex post conservatism on the cost of equity capital: A quantile regression approach for MENA countries
}

\author{
Maha Khalifa \\ Associate Professor of Accounting \\ Faculté des Sciences Juridiques, Economique et de Gestion de Jendouba, \\ University of Jendouba \\ LIGUE-ISCAE, University of Manouba, Tunis, Tunisia \\ Email: khalifa_maha86@yahoo.fr \\ Hakim Ben Othman \\ Full Professor of Accounting and Finance \\ Tunisian Business School (TBS), University of Tunis \\ \& LIGUE-ISCAE, University of Manouba, Tunisia. \\ Email: hakim.benothman@tbs.rnu.tn

\section{Khaled Hussainey*} \\ Full Professor of Accounting and Financial Management \\ Portsmouth Business School \\ University of Portsmouth \\ Room 6.22 Richmond Building, \\ Portland Street \\ Portsmouth, PO1 3DE \\ United Kingdom \\ Email: khaled.hussainey@port.ac.uk
}


(*) Corresponding author

\begin{abstract}
This paper aims to provide a deeper understanding of the relationship between accounting conservatism and the cost of equity capital (COEC). For this purpose, we use the quantile regression $(\mathrm{QR})$ framework and examine the effect of two dimensions of conservatism (ex ante and ex post) on the COEC. This methodological contribution allows us to test whether the effect of the two forms of conservatism vary across the full distribution, especially at the extreme quantiles of the COEC. Empirical results from the QR reveal that the effect of the two dimensions of conservatism considerably differs across COEC quantiles.
\end{abstract}

Keywords: Accounting conservatism cost of equity capital, ex ante conservatism, ex post conservatism, quantile regression, MENA countries.

\title{
Paper type: Research Paper
}

\section{Introduction}

We intend to provide a deeper understanding of the relationship between accounting conservatism and the cost of equity capital. For this purpose, we use the quantile regression approach as introduced by Koenker and Basset (1978) and examine how the two forms of accounting conservatism (ex ante and ex post) affect the variation of the full cost of equity capital distribution, especially at its extreme quantiles.

A number of studies have examined the effect accounting conservatism on the cost of equity capital. However, evidence of such effects, as reported in these studies, is mixed and inconclusive. For example, Francis et al. (2004) report no significant association, Chan et al. (2009) and Biddle et al. (2012) show a positive association, however, Artiach and Clarkson (2014) Garcia et al. (2011), Khalifa and Ben Othman (2015) and Li (2014) find a negative effect of accounting conservatism on the cost of equity capital. The apparent inconsistency of the findings may be ascribed to the regression approach employed to test such association (Rush et al. (2014)). Indeed, a common feature of all previous studies that have sought empirical 
evidence on the association between accounting conservatism and the cost of equity capital, is that they restricted the analysis to the use of the classical ordinary least squares (OLS) regression.

OLS regression revolves around estimating a linear relationship between exogenous variables or covariates $\boldsymbol{X}$, and the conditional mean of an endogenous or target variable, $\mathbf{Y}$. It assumes that the association between the covariates and the target is constant at each point of the distribution of the response variable. If the distribution of the COEC is heterogeneous or if the factors that affect the firms' COEC change their effect from firms with higher COEC to firms with lower COEC, the OLS regression tends to throw away valuable information, as it focuses only on the mean distribution of the COEC without taking into account the entire distribution. In contrast to this, the present study intends to provide a complete description of the COEC's distribution conditioned on accounting conservatism.

For this purpose, our study suggests to use the quantile regression $(\mathrm{QR})$ approach initially introduced by Koenker and Bassett (1978) and examine the effect of two dimensions of accounting conservatism (ex ante and ex post) on the COEC. QR framework has been successfully employed in a variety range of areas of economics and finance to deal with the case where the conditional distribution of the target variable varies considerably with the exogenous variables (for more details, see for example Koenker and Hallock (2001)).

So, our paper contributes to the existing literature by providing a novel approach based on a QR framework to examine whether or not the effect of ex ante and ex post conservatism have inconsistent effects across the whole spectrum of the COEC variable. Generally speaking, QR approach was proved to be more robust than OLS regression (Koenker et al. (2012)) not only when we focus on the association between covariant and target variables at each quantile of the analyzed distribution but also when the target variable shows a major skewness. Our approach 
is therefore able to produce a robust and complete picture of the distribution of the COEC conditioned on the two forms of accounting conservatism (ex ante and ex post). To the best of our knowledge, there has not been a study yet that has examined the association between accounting conservatism and the COEC using the QR approach especially in emerging countries. This paper therefore bridges this gap in accounting literature, especially, using data from MENA emerging countries; we provide further empirical evidence on the impact of ex ante and ex post conservatism on the COEC by allowing estimates to vary across COEC quantiles. We expect that the effect of ex ante and ex post conservatism on the COEC will differ considerably across a range of COEC quantiles. We also differ from previous studies by examining how the effect of ex post conservatism on the COEC can be affected by the ex ante dimension of conservatism. Indeed, we proceed on the Beaver and Ryan's (2005) assumption that ex ante conservatism preempts ex post conservatism and so affect the asymmetric timeliness of earnings.

We are motivated to focus on MENA countries for a number of reasons. First all previous studies on such association use data from developed countries (except Khalifa and Ben Othman, 2014). Second, MENA countries have embarked on an economic and social transition process since 1980 s in order to comply with the requirement of international monetary funds (Ben Othman and Zeghal, 2010). To achieve this aim, MENA countries need to bring foreign capital as far as it is necessary for the development of their financial markets. Foreign investors will therefore be concerned withthe rate of return (Firm's COEC) that receives in exchange for their investments. Moreover, firms in MENA countries are recognized as applying accounting conservatism practices (Khalifa and Ben Othman, (2015) and Khalifa et al., (2016)). Therefore, MENA emerging countries is an interesting context for examining the association between accounting conservatism and the cost of equity. 
Our empirical findings are based on a sample of firms pertaining to 13 countries from the MENA region (i.e. Bahrain, Egypt, Israel, Jordan, Kuwait, Lebanon, Morocco, Oman, Qatar, Tunisia, Turkey, Saudi Arabia and the UAE) for the sample period 2004- 2009. As a first test, we examine the effect of ex ante and ex post conservatism on the COEC using classical OLS regression. Different statistical procedures that rely on OLS regression have been used, including: pooled OLS regression and panel data regression with fixed and random effects models. The findings suggest that, as predicted, the ex ante conservatism is positively associated with the COEC and that ex post conservatism is negatively associated with the COEC. The results are robust to the use of other estimation methods; however, fixed effect model provides a higher explanatory power of total variability compared to the other methods. Our second examination consists in testing the assumption whether ex ante conservatism may affect the association between ex post conservatism and the COEC. To do so, we estimate the model describing the association between ex post conservatism and the COEC conditioning on the ex ante conservatism. Unlike our prediction, we find that the effect of ex post conservatism on the COEC remain unchanged even after introducing ex ante conservatism. Our third test reexamine the association between the two dimensions of accounting conservatism and the cost of equity capital by allowing estimates to vary across COEC quantiles. The results using the QR approach seem to be interesting, as there is a significant change at the value of the coefficient for ex ante and ex post conservatism in different quantiles compared to the OLS results. In particular, we report that for firms with higher COEC the effect of ex ante and ex post conservatism is more pronounced than firms with lower COEC. Moreover, we find that, not only the effect of ex post conservatism on the COEC remains negative even after controlling for ex ante conservatism, but also it increases in value. Likewise, the result of the QR suggests that ex post conservatism has more pronounced intensity for firms with higher COEC. This means that firms with high COEC must use the two forms of accounting conservatism. This 
paper, by using QR approach, sheds more lights on the association between accounting conservatism and the COEC and gives new directions for further research in accounting literature.

The rest of the paper is organized as follows: Section 2 reviews the literature and develops the hypotheses. Section 3 presents the quantile regression approach. Section 4 describes the sample, the variables, and econometric models. Results are presented in section 5. Section 6 concludes.

\section{Literature review and hypotheses development}

\section{A. Literature review}

Recently, a great debate has opened about the impact of accounting conservatism on information risk in equity markets. Opponents of conservatism, like Accounting Standards Board (FASB) and International Accounting Standards Board (IASB) argue that accounting conservatism may have negative effects on equity markets; however proponents consider that the effects are positive. Within this framework, a range of empirical studies start the examination of the economic consequences of accounting conservatism, especially in equity markets (For example, see Rush and Taylor (2015) for a survey of these studies). In particular, one line of this research avenue focuses on studying the impact of accounting conservatism on the COEC.

Francis et al. (2004) study the relationship between earnings quality, as measured by seven attributes including conservatism, and the COEC. They study US firms over the period 19752001. They expect that firms with higher degrees of conservatism as a measure of higher earnings quality support lower COEC. Using the Basu's (1997) model to measure conservatism and the Brav et al (2004) method to estimate the COEC, they find no significant association between accounting conservatism and the COEC.

Chan et al. (2009) investigate the economic consequences of two dimensions of accounting conservatism: ex ante conservatism and ex post conservatism. They argue that conservative 
accounting plays a signal role by disclosing information about the quality of accounting numbers. They expect that the two dimensions convey different information to equity markets. Using a sample of UK non-financial firms observed over the period 1987-1999, they find that ex post conservatism is associated with lower quality of financial information and higher COEC and that ex ante conservatism is associated with higher quality of financial information and lower COEC.

Garcia et al. (2011) test the relationship between conditional conservatism (ex post) and the COEC. Based on a sample of US firms over the period 1975-2003 and using a novel proxy of ex post conservatism introduced by Callen et al. (2010), they find that ex post conservatism negatively affect the COEC as measured by excess average stock return. Their evidence is supported by additional tests, including the employment of other measures of the COEC.

Buidle et al. (2012) study the effect of ex post conservatism on the COEC for US public firms over the period 1986-2008. They document a positive association between ex post conservatism and the COEC. They argue that ex post conservatism leads to information asymmetry, fundamental downside risk and therefore increases firm's COEC.

Artiach and Clarkson (2014) also study the relationship between accounting conservatism and the COEC. They expect that ex post conservatism is inversely related to the COEC. Based on a sample of US listed companies over the period 1985-2000, they find, as expected, a negative relation between conservatism and the COEC. Moreover, they report that this association diminishes for firms with low information asymmetry.

$\mathrm{Li}$ (2015) examines the governance and contracting role of ex post conservatism in reducing the COEC and the cost of debt in an international setting. He finds that firms that pertain to countries with higher degrees of conservatism have lower COEC and lower cost of debt. He also finds that the negative association between conservatism and the COEC "is stronger in countries with stronger rule of law and the negative association between conditional 
conservatism and the cost of debt is stronger in countries with stronger creditor rights" ( $\mathrm{p}$. 556).

More recently, Khalifa and Ben Othman (2015) examine the effect of ex post conservatism on the COEC using data collected from firms in MENA emerging countries for the period of 20042007. They argue that overall conservative accounting enhances the quality of accounting information and therefore reduce the COEC. Using the Estrada (2000, 2001, 2004, and 2007) approach to measure the COEC and Khan and Watts (2009) method to derive ex post conservatism at firm level, they find as expected that ex post conservatism reduce the cost of equity capital.

\section{B. Hypotheses development}

This paper aims at examining the association between the two forms of accounting conservatism (ex ante and ex post) and the cost of equity capital. Ex post conservatism or commonly called conditional conservatism is defined as an accounting system that requires stronger verification to recognize profits versus losses (Basu, (1997); Watts, (2003a)). Under this specification, economic losses are recognized in earnings faster than economic gains. The second form of accounting conservatism is ex ante or unconditional conservatism is referred to the understatement of the book value of net assets relative to their market value (Beaver and Ryan, (2005)). Prior analytical studies establishes that accounting conservatism, in particular ex post conservatism, improves considerably the functioning of equity markets through providing valuable accounting information to market operators (Gietzman and Trombetta, (2003), Guay and Verrechia, (2007)), Suijs, (2008)). To better understand this mechanism, we review three papers that model the link between ex post conservatism and the cost of equity capital. Specially, they argue that ex post conservatism is linked to the cost of equity capital through informational channel. For example, Gietzmann and Trombetta (2003) articulate that ex post conservatism acts as substitute of voluntary disclosure which is empirically recognized 
to reduce the cost of equity capital by decreasing investors' information risk (Diamond and Verrecchia, (1981); Botosan and Plumlee, (2002); Easly and O'Hara, (2004); Hail and Leuz, (2007); Lambert et al., (2011)). In the same avenue, Bagnoli and Watts (2005) establish through a signaling framework that the manager's declaration that financial reports are conservative allows investors in the presence of information asymmetry to infer hidden information about actual and future prospects of the firms. In turn, with more information acquired, investors are more able to assess the firm value and therefore support less estimation risk, thereby the required return rate (cost of equity capital) decreases. From another point of view, Guay and Verrecchia (2007) demonstrate that by imposing stronger verification to recognize positive economic events than negative economic events, the use ex post conservatism encourages managers to adopt a strategic behaviour by fully disclosed accounting information which in turn lead to the reduction of the market discount. Guay and Verrecchia (2007) argue that this is achieved because ex post conservative improve contracting efficiency and reduces agency and litigation costs. These results coincide with the work by Lambert et al. $(2007,2011)$ who demonstrate that increase the amount of information disclosed to the market improve the precision with which market actors can estimate future earnings and therefore reduce the cost of equity capital as investors lowered the required rate of return. Overall ex post conservatism benefits to capital markets by enhancing information quality, decreasing in turn investors' estimation risk which would lead into a significant reduction of the cost of equity capital. Therefore, our first hypothesis states:

H1: Ex post conservatism is expected to reduce the cost of equity capital.

While the literature offers a set of studies that provide insight into the implication of ex post conservatism in capital markets, there is a limited number of papers that empirically address 
the economic consequences ofex ante conservatism (Beaver and Ryan, 2005). Nevertheless, recent studies by Pae et al. (2004), Roychowdhury and Watts (2004), Givoly et al. (2007)and Khan and Watts (2009) established that ex ante conservatism as measured by the market-tobook ratio is negatively associated with ex post conservatism. Moreover, Chan et al. (2009) argue that ex post and ex ante conservatism convey different information about the quality of future earnings into capital markets. Based on the above, our second hypothesis is that:

H2: Ex ante conservatism is expected to increase the cost of equity capital.

Beaver and Ryan (2005) show that ex ante conservatism can prevent ex post conservatism and hence affects the asymmetric timeliness of earnings. In fact, they hypothesize that ex ante conservatism yields to an increase in the part of intangible assets whose costs are immediately recorded or yields unrecorded goodwill such as accelerated depreciation which all of them are subject of ex post conservatism. Hence, our third hypothesis is that:

H3: The effect of ex post conservatism on the cost of equity capital is moderated by ex ante conservatism.

\section{Quantile regression approach}

The classical linear model represents a response variable, commonly called dependent variable or response variable, $\mathbf{Y}$, as a linear function of one or a set ofindependent variables or covariatesX. It uses the ordinary least square (OLS) approach to estimate the parameters in the linear model. OLS regression is based on the mean of the conditional distribution of $\mathbf{Y}$, that is $E(\boldsymbol{Y} \mid \boldsymbol{X})=\boldsymbol{X}^{\prime} \widehat{\boldsymbol{\beta}}$. Formally, let $\left(y_{i t}, x_{i, t}\right) ; i=1,2, \ldots \ldots, N$ and $t=1,2, \ldots \ldots, T$ be a sample

population, where subscript i denotes the $i^{\text {th }}$ firm and t represents the $t^{\text {th }}$ period. The target, $y_{i t}$, 
designate the firm's cost of equity capital, and $x_{i t}$ is $(K \times 1)$ vector of independent variables. The linear relationship between $y_{i t}$ and $x_{i t}$ is expressed as follows:

$$
y_{i t}=x_{i t}^{\prime} \cdot \beta+\varepsilon_{i t}(1)
$$

Where, $\boldsymbol{\beta}(K \times 1$ vector) are unknown parameters to be estimated.

In the OLS method, the parameter estimates are found by minimizing the sum of the squared errors i.e.:

$$
\min \sum_{i}\left(\varepsilon_{i t}\right)^{2}=\sum_{i}\left(y_{i t}-x_{i t}^{\prime} \cdot \beta\right)^{2}
$$

Or one could obtain the estimator vector of $\beta$ according to the following minimization problem:

$$
\min \sum_{i}\left|\varepsilon_{i t}\right|=\sum_{i}\left|y_{i t}-x_{i t}^{\prime} \cdot \beta\right|
$$

Equation (3) gives parameter estimates by minimizing the sum of absolute errors, commonly known as the least absolute deviation (LAD) regression or median regression.

OLS and LAD methods may suffer from a set of limitations which could affect the quality of the estimates. First, OLS or LAD produces estimators that are optimal if errors are iid and follow a normal distribution. However, these assumptions may not hold, especially where the population is heterogeneous. In such case, the mean distribution of $\mathrm{Y}$ is commonly affected by extreme values. Therefore, it is more appropriate to use non-mean-based models.

Second, OLS and LAD methods provide only one estimate based on the central distribution of the dependent variable. This provides only a partial view of the relationship between the response variables and the covariates. In other words, neither the OLS nor the LAD methods take into account the full spectrum of the dependent variable (cost of equity capital) especially in the tail regions. To handle these two issues, other regression models have emerged and one of them is the quantile regression approach. 
The quantile regression, initially introduced by Koenker and Bassett (1978), constitutes an extension of classical least squares estimation of conditional mean models to the estimation of an ensemble of models for conditional quantile functions. Quantiles describe a various subdivisions of a frequency distribution into equal intervals based on the value of the data. Quantile regression is more robust to non-normal errors and outliers. It also gives a larger characterization of the data, allowing us to consider the effect of the exogenous variables on the entire distribution of the endogenous variable, not merely its conditional mean. Furthermore, quantile regression does not need strict assumptions as for classical linear regression like to normality, homoscedasicity or absence of outliers (Johnston and DiNardo, 1997).

Formally, following Koenker and Basset (1978), and assume that the $\theta^{\text {th }}$ quantile of the conditional distribution of the dependent variable $y_{i t}$, is linear in $x_{i t}$, therefore the conditional quantile regression model can be expressed as follows:

$$
\begin{gathered}
y_{i t}=x_{i t}^{\prime} \cdot \beta_{\theta}+\varepsilon_{\theta i t} \\
Q_{\theta}\left(y_{i t} \mid x_{i t}\right) \equiv \inf \left\{y: F_{i t}\left(y_{i t} \mid x_{i t}\right) \theta\right\}=x_{i t}^{\prime} \cdot \beta_{\theta} \\
Q_{\theta}\left(y_{i t} \mid \varepsilon_{\theta i t}\right)=0
\end{gathered}
$$

Where $Q_{\theta}\left(y_{i t} \mid x_{i t}\right)$ represents the $\theta^{\text {th }}$ conditional quantile of $y_{i t}$ on the $(K \times 1)$ vector of independent variables $x_{i t} \cdot \beta_{\theta}$ is the unknown vector of parameters to be estimated for different values of $\theta$ in $[0,1]$; and $\varepsilon_{\theta i t}$ is the error term. The value $F_{i t}\left(. \mid x_{i t}\right)$ denotes the conditional distribution of the target variable conditional on $x_{i t}$. For different value of $\theta$ in $[0,1]$, the quantile regression method permits to visit the entire distribution of $y$ conditional on $x$. The estimator for $\beta_{\theta}$ is obtained through the following minimization problem:

$$
\operatorname{Min} \sum_{i t: \varepsilon_{\theta i t}>0} \theta \times\left|\varepsilon_{\theta i t}\right|+\sum_{i t: \varepsilon_{\theta i t}<0}(1-\theta) \times\left|\varepsilon_{\theta i t}\right|=
$$




$$
\sum_{i t: y_{i t}-x_{i t}^{\prime} \cdot \beta>0} \theta \times\left|y_{i t}-x_{i t}^{\prime} \cdot \beta\right|+\sum_{i t: y_{i t}-x_{i t}^{\prime} \cdot \beta<0}(1-\theta) \times\left|y_{i t}-x_{i t}^{\prime} \cdot \beta\right|
$$

The optimization problem in equation (5) allows us to obtain the $\theta^{\text {th }}$ quantile regression estimator $\hat{\beta}_{\theta}$ by minimizing the absolute value of a weighted sum of the residuals between observed values $y_{i t}$ and fitted values $x_{i t}^{\prime} . \beta$. A weight of $\theta$ is attributed to observations with negative residuals (the first term in equation (5)) and a weight of (1- $\theta)$ to observations with positive residuals (the second term in equation (5)). Comparing equation (5) with equation (2) and (3) reveals one of the important features of the quantile regression that is the estimate values of $\beta_{\theta}$ are not constant but vary across different values of $\theta$. One could use this feature to view how the effect of the independent variables switches across the cost of equity capital quantiles region. It should also be noted that the LAD method is a special case of the quantile regression with $\theta=0.5$. It should be noted that the quantile regression method produces estimation based on the weighted sum of residuals for the entire sample and not for a portion of the sample at that quantile. The equation (5) do not have a simple form, the minimization can be solved using a linear programming techniques (Hao and Naiman, (2007)).

The quantile regression approach has been widely used in economic literature, financial research, corporate governance and other fields outside management sciences. For example Arias et al. (2001), Buchinsky (1994 and 2001) and Eide and Mark (1998) in education economics, Chernozhukov and Umantsev (2001) and Engle and Manganelli (2004) in Value at Risk, Barnes and Highes (2002) in cross-section of stock market return, Basset and Chen (2001) in mutual fund investment styles, Meligkotsidou and Vrontos (2009) in hedge fund strategies, Li and Miu (2010) in bankruptcy prediction, Barreto and Hughes (2004) in economic growth studies, Li and Hwang (2011) in accounting earnings, Ramdani and Witteloostuijn (2010) in corporate governance, Buchinsky (1994), Garcia et al. (2001), Machado and Mata (2001) and Nielsen and Rosholm (2001) in wage analysis. The present study represents the first study that 
applies the quantile regression in accounting conservatism and the quality of financial reporting literature.

\section{Research design}

\section{A. Data and sample selection}

Data is collected from companies followed by S\&P and included in their S\&P/IFC emerging markets indices. While the FTSE institutional shareholder services (ISS) and CLSA focus on, respectively, developed markets and Asian emerging markets, S\&P covers many more countries including MENA emerging markets (Ben Othman and Zeghal, 2010). In our sample, all MENA companies must be domiciled in an emerging market (S\&P/IFCG) or a lesser developed global frontier market (S\&P/IFCG frontier) and be among the most actively traded securities in the market.

The preliminary sample includes all firms from 13 MENA countries (Bahrain, Egypt, Israel, Jordan, Kuwait, Lebanon, Morocco, Oman, Qatar, Tunisia, Turkey, Saudi Arabia, and the UAE) during the period from 2004 to 2009. This provides an initial sample of 8,700 firm-year observations. After eliminating missing data, the set of data contains 3,278 firm-year observations. Table 1 presents this sample selection by year and by country.

\section{(Insert Table 1 about here)}

\section{B. Conservatism and cost of equity capital measures}

\section{B.1 Firm-specific proxy of ex post and ex ante conservatism}

In the present study, we use the Khan and Watts's (2009) method to estimate the value of ex post conservatism at firm level. The choice of such method is mainly motivated by the fact that it uses a well-known and widely used model proposed byBasu (1997) to assess ex post conservatism. The Basu's (1997) model is given according the following model:

$$
N I_{i t}=\alpha_{0}+\alpha_{1} D_{i t}+\beta_{1} R_{i t}+\beta_{2} D_{i t} * R_{i t}+\varepsilon_{i t}
$$


Where, $N I$ is net income before extraordinary items, deflated by the market value of equity at the beginning of the period. RT is annual return calculated by cumulating monthly returns starting from the fourth month after the firm's fiscal year. D is a dummy variable equal to 1 if $\mathrm{RT}$ is negative (bad news) and 0 if RT is positive (good news). Under model (6), $\beta_{1}$ relates the degree to which new good news was impounded in accounting earnings. Similarly, the degree to which bad news was incorporated in earnings is measured by $\beta_{1}+\beta_{2}$ where $\beta_{2}$ is the incremental sensibility of earnings to bad news, and hence represents a measure of the asymmetric timeliness extent (ex post conservatism).

To obtain an ex post conservatism at firm level, Khan and Watts (2009) modify the model in equation (6) by writing $\beta_{1}$ and $\beta_{2}$ as linear functions of firm-specific as follows:

$$
\begin{aligned}
& \beta_{1}=G-\text { score }=\mu_{0}+\mu_{1} \operatorname{SIZE}_{i}+\mu_{2} M T B_{i}+\mu_{3} L E V_{i} \\
& \beta_{2}=C-\text { score }=\lambda_{0}+\lambda_{1} S I Z E_{i}+\lambda_{2} M T B_{i}+\lambda_{3} L E V_{i}
\end{aligned}
$$

Where:

MTB is the market-to-book ratio calculated as market value of equity divided by book value of equity. LEV is leverage defined as long-term and short-term debt deflated by market value of equity. SIZE is the natural log of market value of equity.

Empirical estimators of $\mu_{i}$ and $\lambda_{i}(\mathrm{i}=0, \ldots, 4)$ are constant across firms but vary over time. Cscore and G-score vary across firms through cross-sectional variation in the firm-year characteristics (SIZE, LEV and MTB). To estimate the coefficient within equation (7) and (8), Khan and Watts (2009) use the following annual cross-section regression model: 


$$
\begin{aligned}
& E A R_{i}=\beta_{0}+\beta_{1} D_{i}+R_{i}\left(\mu_{0}+\mu_{1} S_{I Z E_{i}}+\mu_{2} M T B_{i}+\mu_{3} L E V_{i}\right)+D_{i} \\
& \quad * R_{i}\left(\lambda_{0}+\lambda_{1} \operatorname{SIZE}_{i}+\lambda_{2} M T B_{i}+\lambda_{3} L E V_{i}\right)+\left(\delta_{1} S I Z E_{i}+\delta_{2} M T B_{i}+\delta_{3} L E V_{i}\right. \\
& \left.+\delta_{4} D_{i} * S I Z E_{i}+\delta_{5} D_{i} * M T B_{i}+\delta_{6} D_{i} * L E V_{i}\right)+\varepsilon_{i}
\end{aligned}
$$

This equation results from substitution of equation (7) and (8) into equation (6) including additional terms in the last parentheses. After estimating this model, the C-score for each firm at each year is obtained as:

$$
\text { Cscore }=C_{-} C O N S=\hat{\lambda}_{0}+\hat{\lambda}_{1} S I Z E_{i}+\hat{\lambda}_{2} M T B_{i}+\hat{\lambda}_{3} L E V_{i}
$$

With regards to ex ante conservatism, Beaver and Ryan (2005) and Chan et al. (2009) propose to use the Book-to-Market ratio, computed as the ratio of book to market value of equity. Theretofore, ex ante conservatism is measured by:

$$
\text { UCONS }=\text { BTM }=\frac{\text { Bookvalueofequity }}{\text { Marketvalueofequity }}
$$

\section{B.2. Cost of equity capital proxy}

Traditionally the cost of equity capital is estimated through the capital asset pricing model (CAPM) introduced by Sharpe (1964) and Lintner (1965). This method is widely used in the context of developed countries, but it is criticized when applied in an emerging markets framework. Harvey (1995) and Estrada (2000) argue that the problem behind the use of CAPM model arises when estimating systematic risk or market risk. The Classical CAPM supposes that markets are totally efficient to use beta risk in estimating cost of equity capital. However, emerging markets do not have this characteristic. They are considered as partial integrated markets. To estimate the cost of equity for companies in emerging markets, Estrada (2000, 2001, 2004, and 2007) proposes a new method based on the downside risk approach. Especially, the model is as follows:

$$
C O E C_{i}=R f_{U S}+R m_{i} * R P_{W}
$$


Where COC is the cost of equity of the firm $\mathrm{i}, R f_{U S}$ is free risk rate of global market (US market), $R m_{i}$ is the risk measure of firm $\mathrm{i}$ and $R P_{W}$ is the premium risk of the global market. The risk measure proposed by Estrada (2000) is given by:

$$
\mathrm{Rm}_{i}=\frac{\Sigma_{\mu_{i}}}{\Sigma_{W}}
$$

Where :

$$
\Sigma_{\mu_{i}}=\sqrt{\frac{1}{T} \sum\left(R_{i}-\bar{R}\right)^{2}} \text { forall }_{i}<\bar{R}
$$

And

$$
\Sigma_{W}=\sqrt{\frac{1}{T} \sum\left(R_{M}-\bar{R}_{M}\right)^{2}} \text { forall }_{M}<\bar{R}_{M}
$$

$\Sigma_{\mu_{i}}$ and $\Sigma_{W}$ designate respectively the value of downside risk of firm $i$ and the global market.

Where $\mathrm{R}$ is the monthly return of the firm, $\bar{R}$ is the annual average return, $R_{M}$ is the market return and $\bar{R}_{M}$ is the annual average market return.

Finally, the cost of equity capital can be obtained following the Estrada approach as:

$$
\operatorname{COEC}_{i}=R f_{U S}+\frac{\Sigma_{\mu_{i}}}{\Sigma_{W}} *\left(R_{M}-R f_{U S}\right)
$$

\section{Econometric models}

To test our hypotheses, we use three models. Equation (9) is used to test the association between ex post conservatism and the COEC. Equation (10) is estimated to test the effect of ex ante conservatism on the cost of equity capital. Equation (11) is used to examine the effect of ex ante conservatism on the association between ex post conservatism and the COEC. 


$$
\begin{aligned}
& \operatorname{COEC}_{i t}=\beta_{0}+\beta_{1} C_{-} \operatorname{CONS}_{i t}+\beta_{2} \text { BETA }_{i t}+\beta_{3} \operatorname{SIZE}_{i t}+\beta_{4} L E V_{i t}+\sum_{j=1}^{13} \beta_{j} \operatorname{Country}_{j}+\varepsilon_{i t} \\
& \operatorname{COEC}_{i t}=\alpha_{0}+\alpha_{1} U_{-} \operatorname{CONS}_{i t}+\alpha_{2} \text { BETA }_{i t}+\alpha_{3} \operatorname{SIZE}_{i t}+\alpha_{4} \operatorname{LEV}_{i t}+\sum_{j=1}^{13} \alpha_{j} \operatorname{Country}_{j}+\varepsilon_{i t} \\
& \operatorname{COEC}_{i t}=\gamma_{0}+\gamma_{1} C_{-} \operatorname{CONS}_{i t}+\gamma_{2} U_{-} \operatorname{CONS}_{i t}+\gamma_{3} \text { BETA }_{i t}+\gamma_{4} \operatorname{SIZE}_{i t}+\gamma_{5} \mathrm{LEV}_{i t}+\sum_{j=1}^{13} \gamma_{j} \operatorname{Country}_{j}+\varepsilon_{i t}
\end{aligned}
$$

Where COCE is the estimated cost of equity capital of firm i in year t, obtained using Estrarda (2000) approach. C_CONS represents the firm-year proxy of ex post conservatism for firm i at year t, obtained following Khan and Watts (2009) method. U_CONS is a measure of ex ante conservatism calculated as the book value of equity deflated by the market value of equity. We control for factors that may affect the COEC, including risk and country specific effects. For risk factors, we include BETA which represents the slope coefficient from the monthly regression of the capital asset pricing model using 24-month window, SIZE is measured by the natural logarithm of the market value of equity and LEV measured as total debt deflated by market value of equity. For country specific effects, we use a dummy variable, Country $y_{j}$, which takes the value of 1 if the observation is from county $\mathrm{j}, 0$ otherwise.

Both models are first estimated using the OLS regression method under different specification including pooled OLS and panel regression (fixed and random effects). As discussed earlier, this classical approach may suffer from limitations like a departure from normality or the existence of extreme values. Furthermore, OLS and LAD regressions provide only one measure of the central distribution tendency of the dependent variable. To handle the drawbacks of the OLS and LAD methods, models in equations (9), (10) and (11) are estimated using quantile regression. Confidence intervals for each parameter in models (9), (10) and (11) are also reported. Estimation of the matrix of coefficients' standard error in the quantile regression model is made using the bootstrap method. 


\section{Empirical results}

\section{A. Descriptive statistics}

Table 2 reports the relevant descriptive statistics for the variables used in our econometric models. The mean and median values of the dependent variable, COEC, are respectively 0.5823 (58.23\%) and $0.4112(41.12 \%)$ indicating that firms in MENA countries support higher cost of equity capital. The mean and median of ex post conservatism, C_CONS, are -0.1026 and 0.0606, respectively. However the mean (median) of ex ante conservatism, U_CONS, equals $0.6698(0.5489)$ less than one, which indicate that on average in MENA countries, there is an understatement of the book value of equity over the market value of equity indicating the presence of ex ante conservatism. As regard the distribution of our variables, data isnormal distributed if the value of kurtosis is lower than 3 and the value of skewness is zero. In the case where the skewness is equal or close to zero the distribution is said symmetric and if the value of kurtosis is less than 3, the tails of the distribution are thin. We can see that the skewness value for all variables is not close to zero, except SIZE variable where the skwness is equal to 0.0661, indicating that the variables have asymmetric distribution. In addition, the kurtosis value is greater than 3 for all variables, except again SIZE variable. This indicates the presence of observations with extreme values. This means that the distributions of all variables expect SIZE variable have not a bell-shaped (Normal distribution). To confirm this result we conduct a skewness and kurtosis test for normality (using the 'sktest' in STATA's (version 12.0) statistical software). The null hypothesis of the test supposes that data isnormally distributed. If the p-value of the test is lower than 0.05 , the distribution is said non-normal. The result of the test (are not reported here) indicates that all variables (except SIZE) are not normally distributed at the $1 \%$ level of confidence with two degree of freedom. At all, this findings support that quantile regression may be more reasonable to be used instead of the OLS regression. 


\section{(Insert Table 2 about here)}

Table 3 reports a Pearson correlation test for the key variables in our study. As one could expect, the cost of equity capital is negatively correlated with ex post conservatism, C_CONS, and positively correlated with ex ante conservatism, BTM respectively at $1 \%$ and $10 \%$ level. For control variables, as expected, results show that the cost of equity capital is positively correlated with SIZE and negatively correlated with LEV and BETA. Another interesting result is the correlation between C_CONS and U_CONS, which is negative indicating that ex post and ex ante conservatism, are opposite. This result coincides with the findings of Beaver and Ryan (2005) and Chan et al (2009) who argue that ex ante conservatism preempts the application of ex post conservatism.

\section{(Insert Table 3 about here)}

\section{B. Results of pooled OLS and panel regression}

\section{B.1 Ex post conservatism}

Table 4 shows the results of testing the association between ex post conservatism and the COEC. The model in equation (9) was first estimated using pooled OLS regression and as the findings may be affected by outliers we also run a robust OLS regression which permits to smooth the effect of outliers on the coefficient regression. This allows us to check whether the OLS estimations are affected by extreme values. As expected, the C_CONS coefficient presents a negative sign and which is significant at the $1 \%$ level. This finding is in line with prior empirical studies that provide evidence of negative association between ex post conservatism and the COEC such as Garcia et al (2011), Artiach and Clarkson (2014) and Khalifa and Ben Othman (2014). Our results are also consistent with prior analytical work by Gietzman and Trombetta (2003), Bagnoli and Watts (2005) and Guay and Verrecchia (2007) who show that ex post conservatism may act as a substitute of voluntary disclosure which in turn reduce the 
COEC. To check the robustness of our findings, we also perform a panel regression with fixed and random effects to control for firm heterogeneity. The results show that, even controlling for firm heterogeneity, the coefficient of the C_CONS remains negative and significant at the 1\%. However, the fixed effects (FE) model presents a higher R-squared coefficient of determination and a lower BIC and AIC ratios, suggesting that using the fixed effect model to estimate the association between ex post conservatism and the COEC is more appropriate than pooled OLS. With regards to risk factors, we find, as expected, that COEC is negatively associated with SIZE and positively related to BETA. This indicates that larger firms exhibit less cost of equity capital and firms with higher risk support more cost of equity capital. Unfortunately, unlike our expectation we find that LEV is negatively associated with COEC.

\section{(Insert Table 4 about here)}

\section{B.2. Ex ante conservatism}

Table 5 reports the result of our attempt to relate ex ante conservatism, U_CONS, to the cost of equity capital, COEC. We proceed in same manner as for ex post conservatism that is we report the result of four models OLS, OLS robust, FE and RE models. The main result in Table 5 is the magnitude and the sign of the coefficient on U_CONS variable. In all models, we find, as expected, that ex ante conservatism affects positively the cost of equity and the association is significant at $1 \%$ level. This result is in line with the assumption that ex-post and ex-ante conservatism convey different information to capital markets (Chan et al., (2009)). All models are globally significant at $1 \%$ level. Nevertheless, we find again that the FE model is superior over OLS, OLS robust and RE models. Indeed, the FE presents the higher degree of variability explained by the fitted model. The $\mathrm{R}^{2}$ is about $27.48 \%$. Moreover, all estimators are significant at $1 \%$ level in the FE model. The BIC index of FE is lower compared with the other models. Concerning control variables, we find as expected that COEC is positively associated with LEV 
and BETA and negatively related with SIZE which in line with prior studies (Chan et al, (2009); Khalifa and Ben Othman, (2015))

\section{(Insert Table 5 about here)}

Prior studies establish that ex post and ex ante conservatism are correlated (Pope and Walker, (2003); Pae et al., (2005); Beaver and Ryan, (2005); Chan et al, (2009)). They advance that it is more appropriate to test the effect of ex post conservatism on the cost of equity capital by controlling for ex ante conservatism. Following this idea, we empirically test the association between ex post conservatism and the cost of equity capital after controlling for ex ante conservatism. Table 6 reports result of such estimation. The findings are consistent with the results in Tables 4 and 5, indicating that ex post conservatism affects negatively the cost of equity capital even after controlling for ex ante conservatism. Moreover, taking together, the results in Table 4 and Table 6 show that the effect of ex post conservatism on the COEC increases after controlling for ex ante conservatism. The coefficient on ex post conservatism change from -0.712 to -0.8329 suggesting that, in contrast with the expectation of Beaver and Ryan (2005), ex ante conservatism does not preempt the ex post conservatism effect.

\section{(Insert Table 6 about here)}

\section{Results of quantile regression}

The main contribution of the present study is to suggest the quantile regression approach as an advanced econometric method to handle the drawbacks of the classical OLS regression method. As discussed early, descriptive analysis of our data has revealed that the dependent variable, COEC, presents a positively skewed distribution and a kurtosis value greater than 3 indicating the presence of outliers which may cause the non-normality of the dependent variable and therefore violate the normality hypothesis of residuals in OLS regression. This may affect the quality of OLS estimators with regard to the bias and the efficiency. In addition, the OLS 
method produces estimator that only focuses on the central tendency of the COEC distributions. Indeed, it does not permit us to differentiate the effect of ex post and ex ante conservatism on the cost of equity capital in the tail regions, that is, between firms with higher COEC and firms with lower COEC. Therefore, this motivates us to use an alternative approach that is the quantile regression in order to allow this kind of analysis.

\section{C.1 Ex post conservatism and the cost of equity capital}

Table 7 shows the result of the impact of ex post conservatism, C_CONS, on the cost of equity capital, COEC, using quantile regression approach. For simplicity of presentation, the intercept and control variable estimates are excluded from Table 7 . Table 7 shows that the coefficient estimate on ex post conservatism variable, C_CONS is negative and significant for all quantiles indicating that our estimation result is consistent across quantiles. Besides, we find that, as the quantile levels move up, the impact of ex post conservatism on cost of equity capital increase monotonically in magnitude from -0.2225 at the $5^{\text {th }}$ quantile to -0.9413 at the $95^{\text {th }}$ quantile, indicating that the effect of ex post conservatism is more pronounced for firms with higher cost of equity capital. This coincide with theoretical and empirical findings who support the idea that ex post conservatism may play a signal role by allowing managers to provide private information (Gietzman and Trombetta, 2003; Bagnoli and Watts, 2005; Guay and Verrecchia, 2007) and improve the quality of information disclosed, which in turn will reduce the cost of equity capital. As firms that exhibit higher cost of equity capital is synonym of lower information quality and higher information asymmetry, ex post conservatism will have more effect on the cost of equity capital. The two columns at the right of Table 7 present F-tests for testing the differences between slope coefficients across various quantiles. Especially, we test the difference between coefficient estimates at the $\theta$ and $(1-\theta)$ quantiles. Standard errors of estimators are obtained by running quantile regression using bootstrap method. The test reveals that there are significant differences at $1 \%$ level between all quantiles except for the $40^{\text {th }}$ 
quantile versus the $60^{\text {th }}$ quantile and for the $45^{\text {th }}$ quantile versus the $55^{\text {th }}$ quantile. In particular, the difference is more pronounced between firms with higher cost of equity capital and firms with lower cost of equity capital, that is, the $5^{\text {th }}$ quantile versus the $95^{\text {th }}$ quantile and the $10^{\text {th }}$ quantile versus the $90^{\text {th }}$

\section{(Insert Table 7 about here)}

To have a better vision of these results, the effect of ex post conservatism on the cost of equity capital for all quantiles is summarized in Figure 1. This figure is produced in STATA using the command 'grqreg' command after using the 'sqreg' command. In particular, Figure 1 draws the quantile regression estimates of the ex post conservatism variable (solid line) and their 95\% confidence intervals (in shaded area) together with fixed-effect estimate (dashed line). Figure 1shows that the quantile regression estimates vary with quantiles and exhibits a symmetrical Vshape indicating that the effect of ex post conservatism becomes higher moving from lower quantile to upper quantile. We remark also that the $95 \%$ confidence intervals do not overlap with the zero effect line indicating that the coefficient on ex post conservatism is negatively significant for all quantiles.

\section{(Insert Figure 1 about here)}

The estimation result of the relationship involving ex post conservatism with the cost of equity for the control variables across different quantiles and their $95 \%$ confidence intervals are shown in Figure 2. For SIZE variable, the coefficient is negative for all quantiles. It is significant at the $5^{\text {th }}-40^{\text {th }}$ quantiles and not significant for the other quantiles. The coefficient on BETA is negative and not significant for the $5^{\text {th }}-40^{\text {th }}$ and for the $90^{\text {th }}-95^{\text {th }}$ quantiles. It is only positively significant for the $55^{\text {th }}-70^{\text {th }}$ quantiles. For the coefficient on LEV, the estimates are all negatively significant across quantiles. As we move from lower quantiles to upper quantile, the effect of LEV is more pronounced. 


\section{(Insert Figure 1 about here)}

\section{C.2 Ex ante conservatism and the cost of equity capital}

We repeat the above quantile regression analyses to estimate the association between ex ante conservatism, U_CONS, and the cost of equity capital, COEC. The results of quantile regression estimations are reported in Table8. The 95\% confidence intervals together with fixed-effect estimates are displayed in Figure 3 for the ex ante conservatism coefficient and in Figure 4 for control variables. According to the result given in Table 8, the coefficient on ex ante conservatism, U_CONS, is positively significant and vary significantly across different quantiles. Unlike ex post conservatism, the quantile regression estimations show that the coefficient on U_CONS does not increase monotonically with the quantile level. Indeed, it presents two patterns. The coefficient gains in magnitude between the $5^{\text {th }}$ and $65^{\text {th }}$ quantiles but its value decrease between the $70^{\text {th }}$ and $95^{\text {th }}$ quantiles. The F-test for equality of slopes across quantiles shows that difference is significant for all pairs of quantiles at $1 \%$ level. These result that the positive association between ex ante conservatism and the cost of equity capital is rather heterogeneous across the COEC quantiles. Thus, the OLS estimates cannot trace all the picture of the relationship between the cost of equity capital and ex ante conservatism. We see this from Figure 3 where the shaded band (95\% confidence interval for the quantile regression estimates) does not overlap with the horizontal line (the OLS estimate). Note that this result is not predictable a priori, only after running the quantile regression analysis.

\section{Insert Table 8 about here)}

\section{(Insert Figure 3 about here)}

We turn our attention on control variables. Figure 4 reports the estimated coefficients and their 95\% confidence intervals of the OLS (dashed line) and quantile regression (solid line) coefficient estimates for SIZE (Fig 4a), BETA (Fig 4b) and LEV (Fig 4c) in model relating ex 
ante conservatism, U_CONS, with the cost of equity capital, COEC. Overall, the figures show a variation of the coefficients over the quantiles of the COEC. Besides, the $95 \%$ confidence intervals from quantile regression does not overlap the horizontal line that present the OLS estimate, mainly in tail regions. This presents another proof of the OLS's failure in capturing the whole picture of the dependent variable.

\section{(Insert Figure 4 about here)}

\section{C.3 Effect of ex post conservatism on the COEC controlling for ex ante conservatism}

Table 9 shows the result of the QR on the association between ex post conservatism and the COEC after controlling for ex ante conservatism. The reading of the results shows that for all quantiles the coefficient measuring the effect of ex post conservatism on the COEC remains negative and significant at the $1 \%$ level even after controlling for ex ante conservatism. Moreover, the coefficient on ex post conservatism increases in intensity from the $5^{\text {th }}$ quantile to the $95^{\text {th }}$ quantile. Combining the results of Tables 7 and 9 , we remark that for firms with higher COEC, the effect of ex post conservatism on the COEC is more pronounced after controlling for ex ante conservatism. This result suggests that firms having greater COEC must use the two forms of accounting conservatism to reduce the COEC.

\section{(Insert Table 9 about here)}

\section{Conclusion}

Previous studies commonly used ordinary least squares (OLS) method to examine the relationship between an endogenous variable and a set of covariates. The OLS estimation method provides only one set of coefficients which describe the mean effect of the covariates on the dependent variable. However, the quantile regression produces different set of coefficients where each set outlines the form of the relationship between the dependent variable 
and the covariates at a specific quantile of the endogenous variable. Therefore, comparing to the OLS method, quantile regression provides a complete picture on the association between explanatory variables and the dependent variable. The purpose of this study is to re-examine the effect of accounting conservatism on the cost of equity capital using an advanced estimation method, i.e. the quantile regression, which allow us to investigate whether the sign and the significance of the estimated coefficients vary across different quantiles of the cost of equity capital.

Before discussing the quantile regression results, we first replicate the estimations of previous studies by estimating the association between the two dimensions of conservatism, i.e ex ante and ex post, and the cost of equity capital using OLS and panel regression methods. Relying on data from 13 MENA countries and over the period 2004-2009, we find, as predicted, that ex post (ex ante) conservatism is negatively (positively) related to the cost of equity capital in all econometric specifications. This evidence support theoretical underpinning that ex post (ex ante) conservatism affect negatively (positively) the cost of equity capital by enhancing (worsening) information quality. Furthermore, we investigate if ex ante conservatism preempts the effect of conditional conservatism. The result shows that either after controlling for ex ante conservatism, ex post conservatism affects negatively the cost of equity capital with more pronounced magnitude.

Turning to quantile regression results, we find that the effect of ex post and ex ante conservatism vary considerably and significantly across different level of the cost of equity capital. Especially, we find that for firms that exhibit a higher cost of equity capital, the ex post (ex ante) conservatism effect is more pronounced than for firms with lower cost of equity capital. This evidence suggests that the effects of ex ante and ex post conservatism on cost of equity capital are heterogeneous across cost of equity capital's quantiles. The significant heterogeneity in the effect of ex ante and ex post conservatism on the cost of equity capital emphasizes the 
inadequacy of OLS regression which captures only the conditional mean relationship between the cost of equity capital and accounting conservatism and the usefulness of the quantile regression approach, which provide a more complete picture of the effect of conservatism on the cost of equity capital.

The findings of this paper contribute to the literature on the economic consequence of accounting conservatism in several ways. First, in relation to previous studies, we examine the effect of two forms of conservatism, i.e. ex ante and ex post conservatism on the cost of equity capital. Second, as previous studies reported mixed results, we suggest the use of the quantile regression as an advanced estimation method to reconcile conflicting results on the relationship between accounting conservatism and the cost of equity capital. This approach allow us to test if the effectsof ex post or ex ante conservatism, in term of sign and significance, varies across the whole distributionof the cost of equity capital.

The findings of the present paper give empirical evidenceon the benefits of accounting conservatism in capital markets and have several important implications, suggesting that policy makers such as standard-setters and regulators have to accept to develop standards that reconsider accounting conservatism as a desirable attribute of information quality.

Despite the importance of our findings, our paper has limitations with regard to the proxies of variable of interest. Our results rely on one measure of conservatism and cost of equity capital. It will be of importance to check in a future study the robustness of our resultants to the use of other proxies. As a second limitation of our analysis, it should be emphasized that we focus on a specific period of time (2004-2009) and a sample of firms pertaining to 12 MENA countries. Hence our results only reflect this particular period and sample. For a future work, it seems that our estimations can be generalized to other emerging countries and beyond this period of time.

\section{References}


Amihud, Y., and H. Mendelson.. "Asset pricing and the bid-ask spread.” Journal of Financial Economics 17 (1986) 223-249.

Arias, O., K. F. Hallock and W. S. Escudero.'Individual heterogeneity in the returns to schooling: instrumental variables quantile regression using twins data." Empirical Economics, 26 (2001),7-40.

Artiach, T. and Clarkson, P. "Conservatism, disclosure and the cost of equity capital”. Australian Journal of Management, 39 (2014), 293-314.

Bagnoli, M. and Watts, S. “Conservative accounting choices.” Management Science, 51(2005), 786-801.

Barnes, M. L. and Hughes, A. W.“A Quantile Regression Analysis of the Cross Section of Stock Market Returns". (2002) Available at SSRN: http://ssrn.com/abstract=458522.

Barreto, R. A. and A. W. Hughes "Under performers and over achievers: a quantile regression analysis of growth", Economic Record, 80 (2004), 17-35.

Barry, C., and S. Brown. "Differential information and security market equilibrium.” Journal of Financial and Quantitative Analysis 20 (1985), 407-422.

Bassett Jr, G. W. and H. L. Chen. "Portfolio style: return-based attribution using quantile regression”, Empirical Economics, 26 (2001), 293-305.

Basu, S. "The conservatism principle and the asymmetric timeliness of earnings", Journal of Accounting and Economics, 24 (1997), 3-37.

Beaver, W. and Ryan, S. "Conditional and unconditional conservatism: concepts and modeling", Review of Accounting Studies, 10 (2005), 269-309.

Ben Othman, H. and Zeghal, D. "Investigating Transparency and Disclosure Determinants at Firm-Level in MENA Emerging Markets". International Journal of Accounting, Auditing and Performance Evaluation, 6 (2010), 368-396. 
Biddle, G., Ma, M. and Wu, F. "Conditional conservatism and the cost of equity capital: informational, fundamental, and behavioral effects, working paper (2012), University of Hong Kong. Available at http://hkir.ust.hk/hkir/Record/9999-728193

Botosan, C. "Disclosure level and the cost of equity capital", The Accounting Review, 72 (1997), 323-349.

Botosan, C. and Plumlee, M. "A re-examination of disclosure level and the expected cost of equity capital”, Journal of Accounting Research, 40 (2002), pp. 21-40

Brav, A., R. Lehavy, R. Michaely and R. Michaely.. "Using expectations to test asset pricing model", Financial Mangement, 34 (2003), 31-64.

Buchinsky, M. "Changes in the U.S. wage structure 1963-1987: application of quantile regression", Econometrica, 62 (1994), 405-458.

Buchinsky, M. “Quantile regression with sample selection: estimating women's return to education in the U.S”, Empirical Economics, 26 (2001), 87-113.

Callen, J. L., Segal, D., \& Hope, O.-K. “ The pricing of conservative accounting and the measurement of conservatism at the firm-year level". Review of Accounting Studies, 15 (2010), 145-178.

Chan, A. L.-C. , Lin, S. W. J. and Strong, N. "Accounting conservatism and the cost of equity capital: UK evidence", Managerial Finance, 35 (2009), 325 -345.

Chernozhukov, V. and Umantsev, L. "Conditional value-at-risk: Aspects of modeling and estimation”, Empirical Economics, 26 (2001), 271-292

Clarkson, P., J. Guedes, and R. Thompson. "On the diversification, observability, and measurement of estimation risk". Journal of Financial and Quantitative Analysis, 31 (1996), 69-84.

Coles, J., and U. Loewenstein. "Equilibrium pricing and portfolio composition in the presence of uncertain parameters". Journal of Financial Economics, 22 (1988), 279-303. 
Coles, J., U. Loewenstein, and J. Suay. "On equilibrium pricing under parameter uncertainty." Journal of Financial and Quantitative Analysis , 30 (1995), 347-364.

Copeland, T., and D. Galai. "Information effects on the bid-ask spread." Journal of Finance 36 (1983), 1457-1469.

Diamond, D., And Verrecchia, R. "Disclosure, liquidity and the cost of capital", The Journal of Finance, 46 (1991), 1325-1359.

Easly, D.H., and O'Hara, M “Information and the cost of capital”, The Journal of Finance, 59 (2004), 1553-1583.

Eide, E. and H. S. Mark. "The effect of school quality on student performance: a quantile regression approach”, Economics Letters, 58 (1998), 345-350.

Engel, R. and Manganelli, S. "CAViaR: Conditional Autoregressive Value at Risk by Regression Quantiles”. Journal of Business and Economic Statistics, 22 (2004), 367381.

Estrada, J. "The cost of equity in emerging markets: a downside risk approach", Emerging Markets Quarterly, 14 (2000), 19-30.

Estrada, J. "The cost of equity in emerging markets: a downside risk approach (II)", Emerging Markets Quarterly, (2001) 63-72.

Estrada, J. "The cost of equity of internet stocks: a downside risk approach", The European Journal of Finance, 10 (2004), 239-54.

Estrada, J. "Mean-semivariance behavior: downside risk and capital asset pricing", International Review of Economics and Finance, 16 (2007), 169-85.

Francis, J., LaFond, R., Olsson, P. et al. "Costs of equity and earnings attributes." The Accounting Review, 79 (2004), 967-1010.

García Lara , J., GarcíaOsma , B. and Penalva, F. "Conditional conservatism and cost of capital", Review of Accounting Studies, 16 (2011), 247-71. 
Garcia, J., P. J. Hernandez and A. L. Nicolas "How wide is the gap? An investigation of gender wage differences using quantile regression”, Empirical Economics, 26 (2001), 149-167.

Gietzmann, M. and Trombetta, M. "Disclosure interactions: accounting policy choice and voluntary disclosure effects on the cost of rising outside capital." Accounting and Business Research, 33 (2003), 187-205.

Guay, W. and Verrecchia, R. E. Conservative disclosure, Working paper, University of Pennsylvania. Available at http://papers.ssrn.com/sol3/papers.cfm?abstract_id=995562. (2007).

Hail, L. and Leuz, C. "International differences in the cost of equity capital: Do legal institutions and securities regulation matters?” Journal of Accounting Research, 41 (2006), pp. 485531.

Handa, P., and S. Linn. "Arbitrage pricing with estimation risk." Journal of Financial Economics 8 (1993), 1-100.

Hao, L. and D. Q. Naiman (2007).Quantile Regression. London: Sage.

Harvey, C. R. (1995) Predictable risk and returns in emerging markets, The Review of Financial Studies, 8,773-816.

Johnston, J. and J. DiNardo. Econometrics Methods, 4th edn. New York: McGraw-Hill. 1997 Khalifa, M. Ben Othman, H "The effect of conservatism on cost of capital: MENA evidence". Applied Economics, 47 (2015), 71-87.

Khalifa, M., Othman, H.B. and Hussainey, K. "Temporal variation and cross-sectional differences of accounting conservatism in emerging countries", International Journal of Accounting, Auditing and Performance Evaluation, 1 (2016), 45-69.

Khan, M., and Watts, R., "Estimation and empirical properties of a firm-year measure of accounting conservatism” Journal of Accounting and Economics, 48 (2009), 132-150. 
Koenker, R., Bassett, G. “Regression quantiles.” Econometrica, 46 (1978), 33-50.

Koenker, Roger, and Kevin F. Hallock. "Quantile Regression." Journal of Economic Perspectives, 15(2001), 143-156.

Lambert, R., C. Leuz, and R. Verrecchia.. "Accounting information, disclosure, and the cost of capital." Journal of Accounting Research, 45(2007), 385-420.

Lambert, R., Leuz, C. and Verrecchia, R.."Information asymmetry, information precision, and the cost of capital". Review of Finance.16 (2011). 1-29.

Li, M. L. and Hwang, R. N. "Effects of firm size, financial leverage and R\&D expenditures on firm earnings: An analysis using quantile regression approach”, ABACUS, 47 (2011), pp. $182-204$

Li, M-Y L and Miu, P. “A Hybrid Bankruptcy Prediction Model with Dynamic Loadings on Accounting-Ratio-Based and Market-Based Information: A Binary Quantile Regression Approach”. Journal of Empirical Finance, 17 (2010). 818-833.

Li, X. "Accounting Conservatism and the Cost of Capital: An International Analysis." Journal of Business Finance \& Accounting, 42 (2015) 555-582.

Lintner, John. 1965. "The Valuation of Risk Assets and the Selection of Risky Investments in Stock Portfolios and Capital Budgets.” Review of Economics and Statistics. 47 (1965), $13-37$.

Machado, J. A. F. and J. Mata. "Earning functions in Portugal 1982-1994: evidence from quantile regressions", Empirical Economics, 26 (2001), 115-134.

Meligkotsidou L., Vrontos I.D. and Vrontos S.D. "Quantile Regression Analysis of Hedge Fund Strategies". Journal of Empirical Finance, 16 (2009). 264-279.

Nielsen, H. S. and M. Rosholm.'The public-private sector wage gap in Zambia in the 1990s: a quantile regression approach”, Empirical Economics, 26 (2001), 169-182. 
Pae, J., Thornton, D.B. and Welker, M., "The link between earnings conservatism and the price-to-book ratio', Contemporary Accounting Research, Vol. 22 (2005), 693-717.

Ramdani, D. and Witteloostuijn, A. "The impact of board independence and CEO duality on firm performance: A quantile regression analysis for Indonesia, Malaysia, South Korea and Thailand", British Journal of Management, 21 (2010), 607-626.

Roychowdhury, S. and Watts, R. "Asymmetric timeliness of earnings, market-to-book and conservatism in financial reporting", Journal of Accounting and Economics, 44.(2007), $2-31$

Ruch, G.W. et G. Taylor, "Accounting conservatism: A review of the literature”, Journal of Accounting Literature, 34 (2015), 17-38.

Sharpe, William F. 1964. "Capital Asset Prices: A Theory of Market Equilibrium under Conditions of Risk." Journal of Finance. 19 (1964), 425- 42.

Suijs, J. "On the value relevance of asymmetric financial reporting policies". Journal of Accounting Research, 46 (2008), 1297-1321.

Watts, R.L. "Conservatism in accounting part I: Explanations and implications". Accounting Horizons, 17 (2003a), 207-221. 
Table 1: Distribution of firm-year observations over sample period

\begin{tabular}{lcccccccc}
\hline & \multicolumn{7}{c}{ Fiscal year } \\
\cline { 2 - 8 } Country & 2004 & 2005 & 2006 & 2007 & 2008 & 2009 & Total & $(\%)$ \\
\hline Bahrain & 4 & 4 & 1 & 4 & 12 & 1 & 26 & 0.79 \\
Egypt & 9 & 13 & 23 & 23 & 18 & 37 & 123 & 3.75 \\
Israel & 68 & 87 & 105 & 112 & 129 & 132 & 633 & 19.31 \\
Jordan & 58 & 59 & 80 & 85 & 98 & 106 & 486 & 14.83 \\
Kuwait & 26 & 48 & 63 & 74 & 80 & 86 & 377 & 11.50 \\
Lebanon & 2 & 2 & 1 & 4 & 2 & 2 & 13 & 0.40 \\
Morocco & 12 & 27 & 31 & 29 & 22 & 28 & 149 & 4.55 \\
Oman & 31 & 19 & 25 & 37 & 57 & 61 & 230 & 7.02 \\
Qatar & 11 & 21 & 22 & 30 & 23 & 25 & 132 & 4.03 \\
Saudi Arabia & 1 & 4 & 6 & 78 & 37 & 67 & 193 & 5.89 \\
Tunisia & 2 & 14 & 16 & 19 & 16 & 18 & 85 & 2.59 \\
Turkey & 16 & 99 & 114 & 118 & 94 & 155 & 596 & 18.18 \\
UAE & 19 & 32 & 52 & 56 & 44 & 32 & 235 & 7.17 \\
\hline Total & 259 & 429 & 539 & 669 & 632 & 750 & 3278 & 100.00 \\
\hline
\end{tabular}

Table 2: descriptive statistics of dependent/independent variables

\begin{tabular}{cccccccccc}
\hline Variables & mean & \multirow{2}{*}{ Median } & $\begin{array}{c}\text { Std } \\
\text { Dev. }\end{array}$ & Max & Min & Skewness & Kurtosis & Q1 & Q3 \\
\hline SIZE & 5.5425 & 5.5752 & 1.7622 & 11.7930 & 0.4824 & 0.0661 & 2.8745 & 4.2891 & 6.7540 \\
BETA & 0.9202 & 0.8505 & 0.7523 & 5.5457 & -0.5070 & 0.6716 & 3.7751 & 0.2630 & 1.4761 \\
LEV & 0.7113 & 0.1800 & 1.4158 & 13.6790 & 0.0000 & 4.4849 & 28.9989 & 0.0949 & 0.7120 \\
COEC & 0.5823 & 0.4112 & 0.5749 & 3.4720 & 0.0513 & 1.7728 & 6.8923 & 0.1220 & 0.8490 \\
U_CONS & 0.6698 & 0.5489 & 0.5838 & 7.3617 & 0.0340 & 5.1402 & 45.8644 & 0.3672 & 0.8104 \\
C_CONS & -0.1026 & -0.0606 & 0.2288 & 0.5720 & -2.3443 & -3.5903 & 25.7267 & -0.1475 & -0.0026 \\
\hline
\end{tabular}

This table shows descriptive statistics for 1.175 firm-year observations during the period ranges from 2004 to 2007 . It reports the mean, median, standard deviation, minimum, maximum, skewness, kurtosis, first (25\%) and third (75\%) quartiles. COEC is the cost of equity capital estimated using downside risk. C_CONS is a firm-year specific proxy of conditional conservatism obtained following Khan and Watts (2009) methodology. U_CONS is a firm year value of unconditional conservatism measured by the book-to-market value of equity ratio. BETA is the slope coefficient from the monthly regression of the capital asset pricing model using 24-month window.. SIZE is the log of equity market value. LEV is leverage defined as total debt deflated by market value of equity. 
Table 3: Correlation coefficient of dependent/independent variables

\begin{tabular}{ccccccc}
\hline Variables & COEC & C_CONS & BETA & U_CONS & SIZE & LEV \\
\hline COEC & 1.000 & & & & & \\
C_CONS & $--0.221^{* *}$ & 1.000 & & & & \\
& $(0.000)$ & ---- & & & & \\
BETA & -0.0044 & -0.0405 & 1.000 & & & \\
& $(0.877)$ & $(0.154)$ & ---- & & & \\
U_CONS & 0.0535 & $-0.4502^{* *}$ & -0.0209 & 1.000 & & \\
& $(0.059)$ & $(0.000)$ & $(0.463)$ & ---- & & \\
SIZE & 0.0481 & $-0.3116^{* *}$ & $0.0559^{*}$ & $0.3645^{* *}$ & 1.000 & \\
& $(0.090)$ & $(0.000)$ & $(0.048)$ & $(0.000)$ & ---- & \\
LEV & -0.0468 & $-0.3814^{* *}$ & $0.1755^{* *}$ & 0.0079 & $-0.1002^{* *}$ & 1.000 \\
& $(0.108)$ & $(0.000)$ & $(0.000)$ & $(0.786)$ & $(0.000)$ & ----- \\
\hline
\end{tabular}

Note: The value in the parenthesis denotes p-value. $*$ and $* *$ denote significance at the $1 \%$ and $5 \%$ levels, respectively.

This table reports Pearson correlation matrix for our variables of interest where COEC is the cost of equity capital estimated using downside risk. C_CONS is a firm-year specific proxy of ex post conservatism obtained following Khan and Watts (2009) methodology. U_CONS is a firm year value of unconditional conservatism measured by the book-to-market value of equity ratio. BETA is the slope coefficient from the monthly regression of the capital asset pricing model using 24month window. SIZE is the log of equity market value. LEV is leverage defined as total debt deflated by market value of equity. 
Table 4: The relationship between ex post conservatism and the cost of equity capital: OLS regression

\begin{tabular}{|c|c|c|c|c|c|}
\hline \multirow{2}{*}{\multicolumn{2}{|c|}{$\begin{array}{l}\text { Dependent } \\
\text { COEC }\end{array}$}} & \multicolumn{2}{|c|}{ Pooled OLS regression } & \multicolumn{2}{|c|}{ Panel regression } \\
\hline & & OLS & $\begin{array}{l}\text { OLS } \\
\text { robust }\end{array}$ & Fixed effect (FE) & $\begin{array}{c}\text { Random Effect } \\
\text { (RE) }\end{array}$ \\
\hline \multirow{2}{*}{\multicolumn{2}{|c|}{ Constant }} & $0.623 * *$ & $0.478^{* *}$ & $1.338^{* *}$ & $0.629 * *$ \\
\hline & & $(0.000)$ & $(0.000)$ & $(0.000)$ & $(0.000)$ \\
\hline \multirow{2}{*}{\multicolumn{2}{|c|}{ BETA }} & 0.022 & $0.042 *$ & $0.077 * *$ & 0.025 \\
\hline & & $(0.296)$ & $(0.014)$ & $(0.006)$ & $(0.238)$ \\
\hline \multirow{2}{*}{ SIZE } & & -0.017 & -0.014 & $-0.121 *$ & -0.017 \\
\hline & & $(0.077)$ & $(0.059)$ & $(0.015)$ & (0.099) \\
\hline \multirow{2}{*}{\multicolumn{2}{|c|}{ LEV }} & $-0.067 * *$ & $-0.039 * *$ & $-0.343 * *$ & $-0.076 * *$ \\
\hline & & $(0.000)$ & $(0.000)$ & $(0.000)$ & $(0.000)$ \\
\hline \multirow{2}{*}{\multicolumn{2}{|c|}{ C_CONS }} & $-0.712 * *$ & $-0.603 * *$ & $-0.834 * *$ & $-0.707 * *$ \\
\hline & & $(0.000)$ & $(0.000)$ & $(0.000)$ & $(0.000)$ \\
\hline$F / \chi^{2}$ & & $20.91 * *$ & $24.31 * *$ & $38.31 * *$ & $86.59^{* *}$ \\
\hline $\mathrm{R}^{2}(\%)$ & & 6.67 & 7.67 & 19.15 & 6.62 \\
\hline $\mathrm{BIC}$ & & 1944.425 & 1944.425 & 1161.611 & 1958.563 \\
\hline AIC & & 1919.08 & 1919.08 & 1136.266 & 1923.08 \\
\hline \multicolumn{6}{|c|}{ 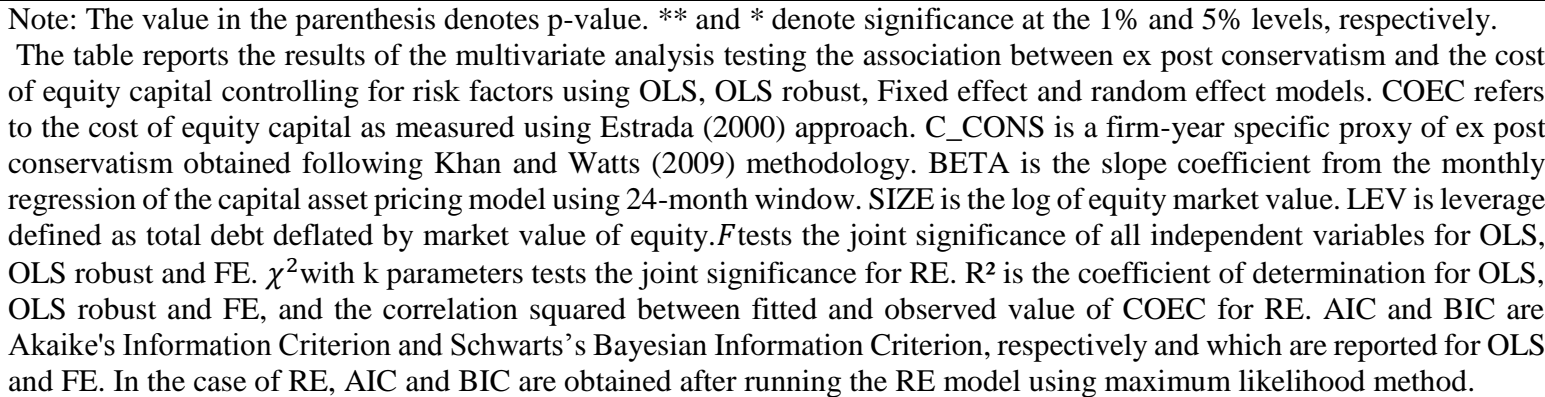 } \\
\hline
\end{tabular}


Table 5: the relationship between unconditional conservatism and the cost of equity capital: OLS regression

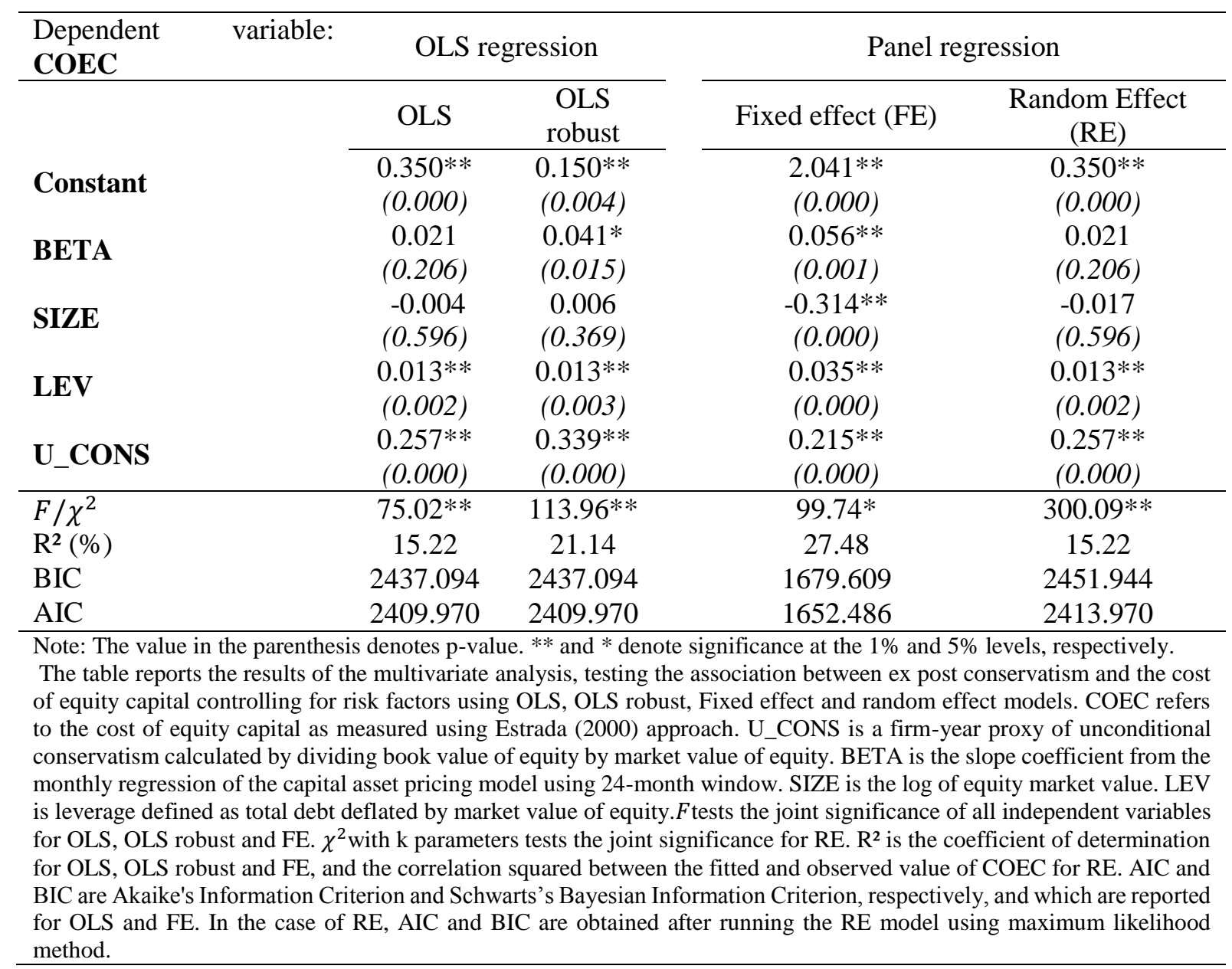


Table 6: The association between ex post conservatism and the cost of equity capital after controlling for unconditional conservatism

\begin{tabular}{lcccccc}
\hline Variable & Coefficient & Std. Err. & $\mathrm{t}$ & $\mathrm{P}>|\mathrm{t}|$ & \multicolumn{2}{c}{$[95 \%$ Conf. Interval] } \\
\hline Constant & 0.6149 & 0.3806 & 1.62 & 0.107 & -0.1325 & 1.3624 \\
BETA & 0.0779 & 0.0278 & 2.80 & 0.005 & 0.0232 & 0.1327 \\
SIZE & -0.0260 & 0.0600 & -0.43 & 0.665 & -0.1439 & 0.0918 \\
LEV & $-0.3206^{* *}$ & 0.0312 & -10.27 & 0.000 & -0.3819 & -0.2593 \\
U_CONS & $0.2579^{* *}$ & 0.0903 & 2.85 & 0.004 & 0.0805 & 0.4354 \\
C_CONS & $-0.8329 * *$ & 0.0990 & -8.41 & 0.000 & -1.0273 & -0.6385 \\
\hline$F$ & $32.62^{* *}$ & & & \\
$\mathrm{R}^{2}(\%)$ & 20.16 & & & \\
\hline Note: The value in the parenthesis denotes p-value. $* * *$ denotes significance at 1\% . \\
The table reports the results of the multivariate analysis testing the association between conditional conservatism \\
and the cost of equity capital controlling for risk factors and unconditional conservatism using Fixed effect model. \\
COEC refers to the cost of equity capital as measured using Estrada (2000) approach. C_CONS is a firm-year \\
specific proxy of ex post conservatism obtained following Khan and Watts (2009) methodology. U_CONS is a firm- \\
year proxy of unconditional conservatism calculated by dividing book value of equity by market value of equity. \\
BETA is the slope coefficient from the monthly regression of the capital asset pricing model using 24-month \\
window. SIZE is the log of equity market value. LEV is leverage defined as total debt deflated by market value of \\
equity.Ftests the joint significance of all independent variables. $\mathrm{R}^{2}$ is the coefficient of determination. \\
\hline
\end{tabular}


Table 7: Impact of ex post conservatism (C_CONS) on the cost of equity capital (COEC) across quantiles.

\begin{tabular}{|c|c|c|c|c|c|c|c|c|c|c|}
\hline \multicolumn{8}{|c|}{ Estimate result of quantile regression } & \multicolumn{3}{|c|}{$\begin{array}{l}\text { Tests of the equality of slope estimates across } \\
\text { quantiles }\end{array}$} \\
\hline Quantiles & Estimate & p-value & Pseudo R²(\%) & Quantile & Estimate & p-value & $\begin{array}{l}\text { Pseudo } \\
\mathrm{R}^{2} / \mathrm{R}^{2}(\%)\end{array}$ & Quantile & F-statistics & p-value \\
\hline 0.05 & $-0.2225 * *$ & $(0.000)$ & 2.31 & 0.95 & $-0.9413 * *$ & $(0.000)$ & 5.52 & 0.05 vs. 0.95 & $4.42 *$ & $(0.035)$ \\
\hline 0.10 & $-0.3268 * *$ & $(0.000)$ & 3.29 & 0.90 & $-0.9621 * *$ & $(0.000)$ & 4.69 & 0.10 vs. 0.90 & $10.30 * *$ & $(0.001)$ \\
\hline 0.15 & $-0.3386 * *$ & $(0.000)$ & 4.06 & 0.85 & $-0.8306 * *$ & $(0.000)$ & 4.33 & 0.15 vs. 0.85 & $8.04 * *$ & $(0.004)$ \\
\hline 0.20 & $-0.4157 * *$ & $(0.000)$ & 4.72 & 0.80 & $-0.7548 * *$ & $(0.000)$ & 4.38 & 0.20 vs. 0.80 & $4.90^{*}$ & $(0.027)$ \\
\hline 0.25 & $-0.4785 * *$ & $(0.000)$ & 5.25 & 0.75 & $-0.7461 * *$ & $(0.000)$ & 4.27 & 0.25 vs. 0.75 & 3.35 & $(0.067)$ \\
\hline 0.30 & $-0.4973 * *$ & $(0.000)$ & 5.29 & 0.70 & $-0.8412 * *$ & $(0.000)$ & 4.51 & 0.30 vs. 0.70 & $6.48 *$ & $(0.011)$ \\
\hline 0.35 & $-0.5945 * *$ & $(0.000)$ & 4.90 & 0.65 & $-0.8601 * *$ & $(0.000)$ & 4.85 & 0.35 vs. 0.65 & $5.18^{*}$ & $(0.023)$ \\
\hline 0.40 & $-0.7124 * *$ & $(0.000)$ & 4.52 & 0.60 & $-0.8237 * *$ & $(0.000)$ & 5.00 & 0.40 vs. 0.60 & 1.00 & $(0.316)$ \\
\hline 0.45 & $-0.7025 * *$ & $(0.000)$ & 4.58 & 0.55 & $-0.7595 * *$ & $(0.000)$ & 5.07 & 0.45 vs. 0.55 & 0.75 & $(0.386)$ \\
\hline 0.50 (LAD) & $-0.7179 * *$ & $(0.000)$ & 4.85 & & & & & & & \\
\hline $\begin{array}{l}\text { Note: The va } \\
\text { The table re } \\
\text { multiple reg } \\
\text { equity capita } \\
\text { The F-tests } \mathrm{f}\end{array}$ & $\begin{array}{l}\text { de in parenth } \\
\text { rts the resul } \\
\text { ssion metho } \\
\text { we only rep } \\
\text { the differer }\end{array}$ & $\begin{array}{l}\text { denotes th } \\
\text { the multi } \\
\text { gy includir } \\
\text { he coeffici } \\
\text { of slope pa }\end{array}$ & $\begin{array}{l}\text { p-value. } * * \text { and } \\
\text { riate analysis test } \\
\text { the three risk fac } \\
\text { at estimates on } C \\
\text { ameters at the } \theta\end{array}$ & denote sig & $\begin{array}{l}\text { ficance at th } \\
\text { t of ex post } \\
\text { ETA and L } \\
\text { ble. } \\
\text { quantiles are }\end{array}$ & $\begin{array}{l}\text { ad } 5 \% \text { leve } \\
\text { vatism on } \\
\text { nce we for } \\
\text { ted in the }\end{array}$ & $\begin{array}{l}\text { s, respectiv } \\
\text { e cost of ec } \\
\text { is on the as }\end{array}$ & $\begin{array}{l}\text { Ising quantil } \\
\text { ween ex post } \\
\text { f this table. }\end{array}$ & $\begin{array}{l}\text { ession ap } \\
\text { rvatism }\end{array}$ & $\begin{array}{l}\text { ch. It adopts a } \\
\text { he cost of }\end{array}$ \\
\hline
\end{tabular}


Table 8: Impact of ex ante conservatism (U_CONS) on the cost of equity capital (COEC) across quantiles.

\begin{tabular}{|c|c|c|c|c|c|c|c|c|c|c|}
\hline \multirow[b]{2}{*}{ Quantiles } & \multicolumn{7}{|c|}{ Estimate result of quantile regression } & \multicolumn{3}{|c|}{$\begin{array}{l}\text { Tests of the equality of slope estimates across } \\
\text { quantiles }\end{array}$} \\
\hline & Estimate & $p$-value & $\begin{array}{l}\text { Pseudo } \\
\mathrm{R}^{2}(\%)\end{array}$ & Quantile & Estimate & p-value & $\begin{array}{l}\text { Pseudo } \\
\mathrm{R}^{2}(\%)\end{array}$ & Quantile & F-statistics & $P$-value \\
\hline 0.05 & 0.0105 & $(0.062)$ & 0.3 & 0.95 & $0.1970 * *$ & $(0.000)$ & 5.12 & 0.05 vs. 0.95 & $11.51 * *$ & $(0.000)$ \\
\hline 0.10 & $0.0261 * *$ & $(0.001)$ & 0.5 & 0.90 & $0.2666 * *$ & $(0.000)$ & 8.08 & 0.10 vs. 0.90 & $38.00 * *$ & $(0.000)$ \\
\hline 0.15 & $0.0416 * *$ & $(0.001)$ & 0.71 & 0.85 & $0.2742 * *$ & $(0.000)$ & 9.15 & 0.15 vs. 0.85 & $35.65 * *$ & $(0.000)$ \\
\hline 0.20 & $0.0809 * *$ & $(0.001)$ & 1.25 & 0.80 & $0.3145^{* *}$ & $(0.000)$ & 9.93 & 0.20 vs. 0.80 & $30.10 * *$ & $(0.000)$ \\
\hline 0.25 & $0.1541 * *$ & $(0.000)$ & 2.33 & 0.75 & $0.3755^{* *}$ & $(0.000)$ & 10.61 & 0.25 vs. 0.75 & $24.54 * *$ & $(0.000)$ \\
\hline 0.30 & $0.1688 * *$ & $(0.000)$ & 3.75 & 0.70 & $0.4057 * *$ & $(0.000)$ & 11.45 & 0.30 vs. 0.70 & $27.46^{* *}$ & $(0.000)$ \\
\hline 0.35 & $0.2601 * *$ & $(0.000)$ & 5.97 & 0.65 & $0.4212 * *$ & $(0.000)$ & 11.61 & 0.35 vs. 0.65 & $18.96 * *$ & $(0.000)$ \\
\hline 0.40 & $0.2915^{* *}$ & $(0.000)$ & 8.32 & 0.60 & $0.4143 * *$ & $(0.000)$ & 11.70 & 0.40 vs. 0.60 & $13.27 * *$ & $(0.000)$ \\
\hline 0.45 & $0.3256^{* *}$ & $(0.000)$ & 10.46 & 0.55 & $0.3937 * *$ & $(0.000)$ & 11.77 & 0.45 vs. 0.55 & $4.95 *$ & $(0.026)$ \\
\hline 0.50 (LAD) & $0.3701 * *$ & $(0.000)$ & 11.46 & & & & & & & \\
\hline
\end{tabular}

Note: The value in parenthesis denotes the p-value. $* *$ and $*$ denote significance at the $1 \%$ and $5 \%$ levels, respectively.

The table reports the results of the multivariate analysis testing the impact of ex post conservatism on the cost of equity capital using quantile regression approach. It adopts a multiple regression methodology including the three risk factors (SIZE, BETA and LEV). Since we focus on the association between ex ante conservatism and the cost of equity capital, we only report the coefficient estimates on U_CONS variable.

The F-tests for the differences of slope parameters at the $\theta$ and $(1-\theta)$ quantiles are presented in the two right-hand columns of this table. 
Table 9: Impact of ex post conservatism (C_CONS) on the cost of equity capital (COEC) conditioned by ex ante conservatism using QR approach

\begin{tabular}{|c|c|c|c|c|c|c|c|c|c|c|}
\hline \multirow[b]{2}{*}{ Quantiles } & \multicolumn{7}{|c|}{ Estimate result of quantile regression } & \multicolumn{3}{|c|}{$\begin{array}{l}\text { Tests of the equality of slope estimates across } \\
\text { quantiles }\end{array}$} \\
\hline & Estimate & $p$-value & $\begin{array}{l}\text { Pseudo } \\
\mathrm{R}^{2}(\%)\end{array}$ & Quantile & Estimate & $p$-value & $\begin{array}{l}\text { Pseudo } \\
\mathrm{R}^{2}(\%)\end{array}$ & Quantile & F-statistics & $P$-value \\
\hline 0.05 & $-0.1597 * *$ & $(0.062)$ & 1.08 & 0.95 & $-2.1145 * *$ & $(0.000)$ & 11.21 & 0.05 vs. 0.95 & $26.09 * *$ & $(0.000)$ \\
\hline 0.10 & $-0.2749 * *$ & $(0.001)$ & 1.79 & 0.90 & $-2.2559 * *$ & $(0.000)$ & 11.98 & 0.10 vs. 0.90 & $75.50 * *$ & $(0.000)$ \\
\hline 0.15 & $-0.3677 * *$ & $(0.001)$ & 2.30 & 0.85 & $-2.1263 * *$ & $(0.000)$ & 13.46 & 0.15 vs. 0.85 & $98.26 * *$ & $(0.000)$ \\
\hline 0.20 & $-0.5273 * *$ & $(0.001)$ & 3.02 & 0.80 & $-2.0738 * *$ & $(0.000)$ & 14.65 & 0.20 vs. 0.80 & $86.69 * *$ & $(0.000)$ \\
\hline 0.25 & $-0.6944 * *$ & $(0.000)$ & 3.99 & 0.75 & $-2.144 * *$ & $(0.000)$ & 15.81 & 0.25 vs. 0.75 & $62.37 * *$ & $(0.000)$ \\
\hline 0.30 & $-0.8266^{* *}$ & $(0.000)$ & 5.13 & 0.70 & $-1.9315 * *$ & $(0.000)$ & 16.62 & 0.30 vs. 0.70 & $32.60 * *$ & $(0.000)$ \\
\hline 0.35 & $-1.0932 * *$ & $(0.000)$ & 6.55 & 0.65 & $-1.9102 * *$ & $(0.000)$ & 17.09 & 0.35 vs. 0.65 & $17.44 * *$ & $(0.000)$ \\
\hline 0.40 & $-1.3584 * *$ & $(0.000)$ & 8.36 & 0.60 & $-1.8473 * *$ & $(0.000)$ & 16.69 & 0.40 vs. 0.60 & $8.02 * *$ & $(0.000)$ \\
\hline 0.45 & $-1.4626^{* *}$ & $(0.000)$ & 10.28 & 0.55 & $-1.9140 * *$ & $(0.000)$ & 15.32 & 0.45 vs. 0.55 & $9.64 * *$ & $(0.026)$ \\
\hline 0.50 (LAD) & $-1.7852 * *$ & $(0.000)$ & 12.52 & & & & & & & \\
\hline
\end{tabular}

The table reports the results of the multivariate analysis testing the impact of ex post conservatism on the cost of equity capital using quantile regression approach. It adopts a multiple regression methodology including the three risk factors (SIZE, BETA and LEV) and controlling for ex ante conservatism. Since we focus on the association between ex ante conservatism and the cost of equity capital, we only report the coefficient estimates on C_CONS variable.

The F-tests for the differences of slope parameters at the $\theta$ and $(1-\theta)$ quantiles are presented in the two right-hand columns of this table. 
Figure 1 Impact of ex post conservatism (C_CONS) on the cost of equity capital (COEC): Quantile regression estimates with $95 \%$ confidence intervals Vs. OLS estimate

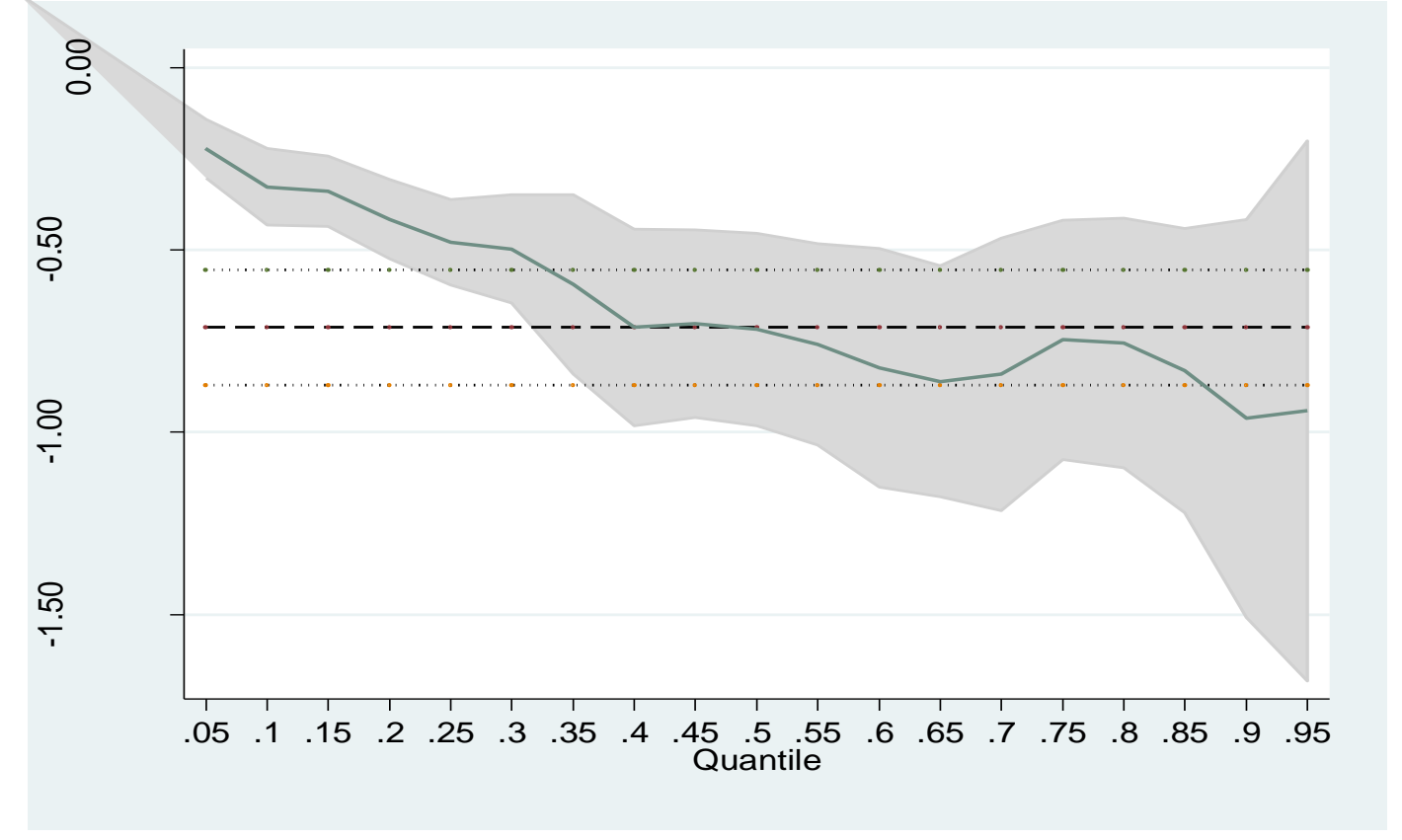

Figure 2: Coefficient estimates and $95 \%$ confidence intervals for size (SIZE), beta (BETA) and leverage $(L E V)$ in the quantile regressions of ex post conservatism

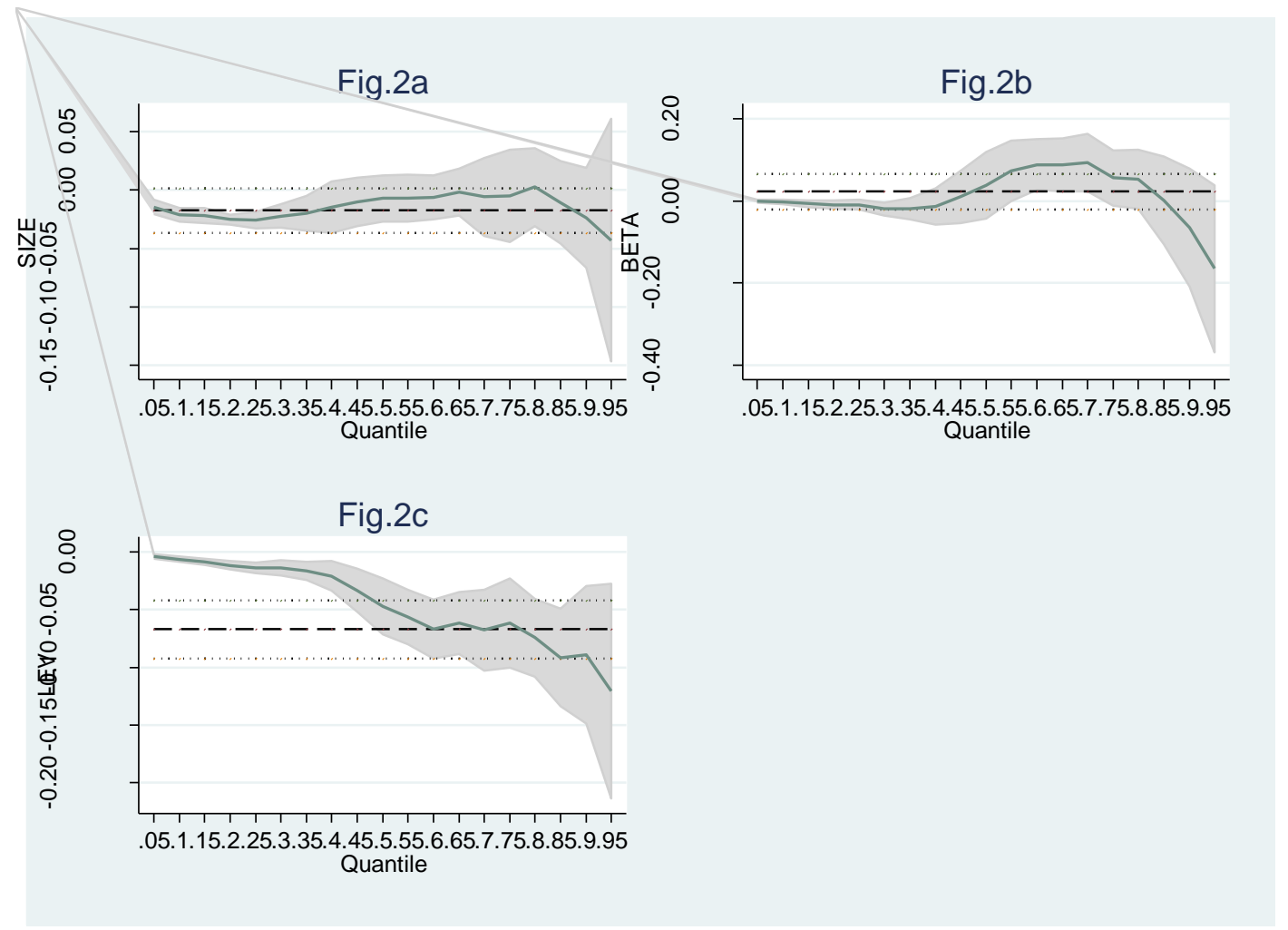


Figure 3 Impact of ex ante conservatism (U_CONS) on the cost of equity capital (COEC): Quantile regression estimates with $95 \%$ confidence intervals Vs. OLS estimate

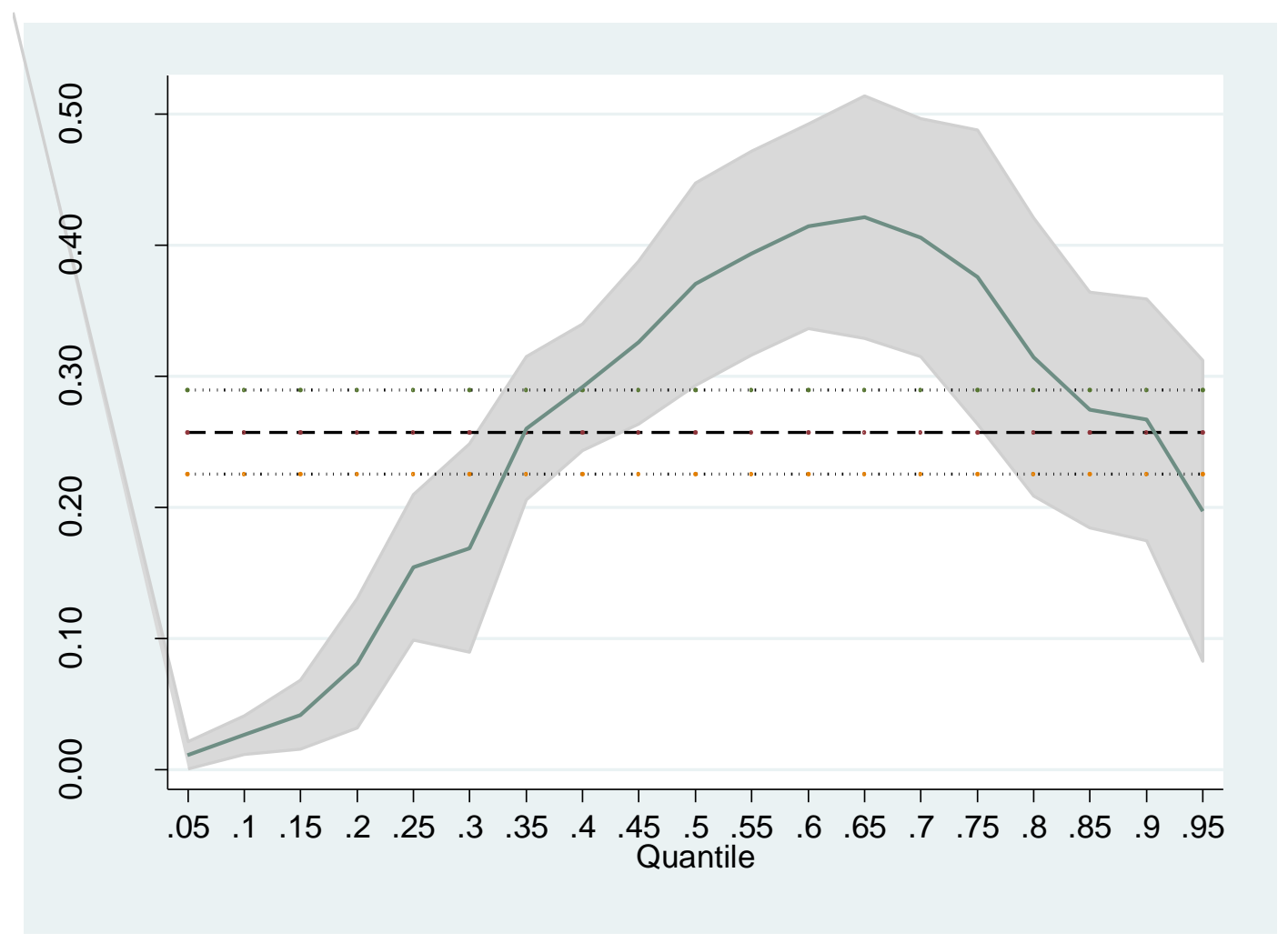

Figure 4: Coefficient estimates and 95\% confidence intervals for beta (BETA), leverage $(L E V)$, and size $(S I Z E)$ in the quantile regressions of ex ante conservatism 


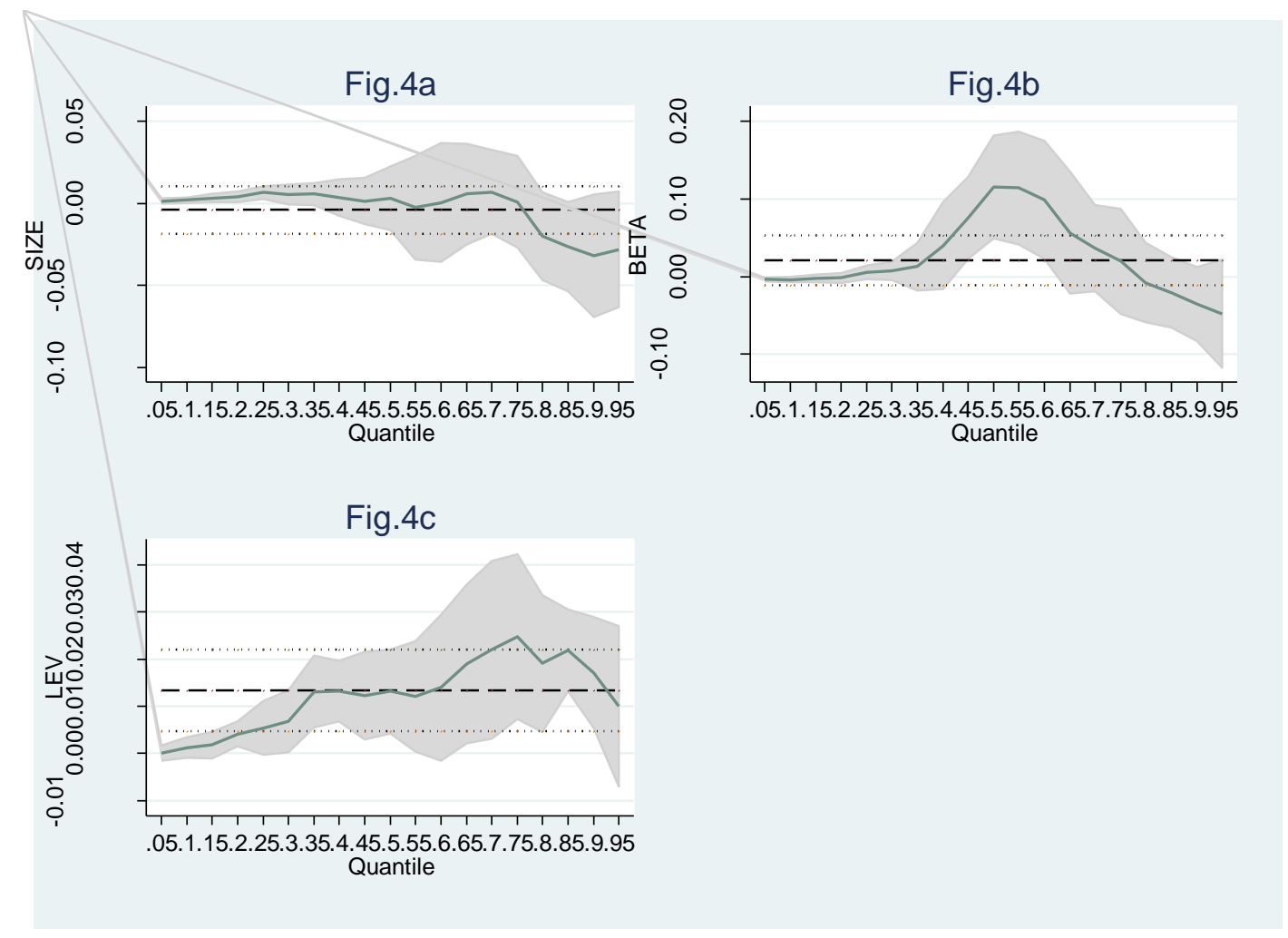

